\title{
A Declaration of Healthy Dependence: The case of home care
}

\author{
Elin Palm
}

\section{Linköping University Post Print}

\section{Tweet}

N.B.: When citing this work, cite the original article.

The original publication is available at www.springerlink.com:

Elin Palm, A Declaration of Healthy Dependence: The case of home care, 2014, Health Care Analysis, (22), 4, 385-404.

http://dx.doi.org/10.1007/s10728-012-0228-x

Copyright: Springer Verlag (Germany)

http://www.springerlink.com/?MUD=MP

Postprint available at: Linköping University Electronic Press

http://urn.kb.se/resolve?urn=urn:nbn:se:liu:diva-87095 


\section{A declaration of healthy dependence - the case of self-care}

\section{Introduction}

With aging populations (UN report, 2009), ${ }^{1}$ chronic diseases are estimated to increase and individuals are predicted to spend a larger part of their lives in poor health. Concomitantly, the need for health- and social services is taken to increase (Kinsella and Velkoff, 2002) and novel forms of health-care are called for. "Aging in place" is a frequently expressed ideal for future health care systems (Kenner, 2008) enabling individuals' to receive support and care services outside traditional care institutions (EU e-Health Action Plan, 2011, OECD Health Policy Studies, 2010). Tele-health and e-health are suggested as cost-effective alternatives to traditional health-care (Noel et al., 2004). "Somatic surveillance" i.e. technological monitoring of- and intervention in bodily functions, is increasingly used as tools for health-care management (Lyon, 2003, Monahan and Wall, 2007, Kenner, 2008). Assistive technology is used within social care (Leece and Peace, 2010) to promote home-based care and reduce the need for institutionalized care. "Many remote home health care systems allow individuals to personalize and customize devices, with the goal of enabling greater patient freedom, reducing costs, and improving the ability for patients to be able to follow the wellness and treatment plans created for them by their medical practitioners" (Cavoukian et al., 2010). Frail elderly and other fragile medical populations are increasingly set up with in-home sensors and other devices that can monitor their daily living activities and notify care professionals or kinpersons when in need of intervention (Kenner, 2008, Cavoukian, 2010, Palm, 2010). By means of monitoring devices, care recipients" homes are made "smart" (Magjarevic, 2007) recording and transmitting person-specific information to care units, enabling health-care professionals to detect anomalies requiring professional intervention or communication with the patient to support his or her self-management. Portable medical devices facilitate patient-centered care and enable care recipients to communicate with a medical center from home. Thus, corrective actions can be taken at an early stage to avert the onset of health problems and avoid hospitalization (Steg et al., 2006).

Health-care programs suggest ICT-based home care as a cost-effective alternative to traditional institutionalized care (OECD, 2010, EU Health plans, 2011, Leece and Peace, 2010) and aim to increase independence, mobility, safety, social interaction and e-inclusion (Magjarevic, 2007). An underlying assumption is that individuals in general prefer independence and the possibility of receiving care at home rather than in any institutionalized form (Kenner, 2008).

\footnotetext{
${ }^{1}$ http://www.oecd.org/dataoecd/20/23/2431724.pdf, http://www.who.int/topics/ageing/en/index.html
} 
Certainly, home-based care implies benefits. Self-monitoring systems and home-care equipment render health care more flexible, mobile and less dependent on traditional care units. Care recipients may receive more frequent attendance, continuous monitoring of vital signs and quick response to alarms by professional care providers while remaining at home. Wireless technologies support care recipients to go on with their lives as normally while staying at home. Assistive technology in the form of interactive robots, sensors and cameras can prolong the time that elderly or handicapped persons can remain at home, enabling remote attendance and support in day-to-day care (Bemelmans, 2010, Broekens, 2009). Such technologies may prevent separations of elderly couples who wish to remain living together postponing the need for an assisted-living facility (Palm, 2010). Personalized health monitoring can offer more frequent remote attendance. Conversely, the practical need for face-to-face meetings between care recipient and formal care-provider decreases. Still, the well-documented emotional need for a certain type of recognition in meetings with health-care professionals will remain the same (Fine and Spencer, 2009). An apprehension is that in result of distance monitoring, care recipients with weak social networks who experience less frequent contacts with health-care professionals may become socially isolated (Palm, 2010, Nordgren, 2011). Hence, to what extent is independence a reasonable aim for the future health care?

This article investigates the meaning and value of independence in relation to self-care. First, the increasing use of technology-based self-care is described. Second, examples are provided of how independence is promoted and described in relation to self-care by health-care planners, care providers and developers of home-care technology. Third, an interpretation of the meaning and value of those examples are provided. Fourth, possible practical and ethical implications of an emphasis on independence as described in health-care policies/plans and by self-care technology developers are sketched. Fifth, a reasonable understanding of independence for future health care is suggested. Sixth, findings are summarized and conclusions provided.

\section{Self-care}

Aging populations has become a major concern in the developed world and are expected to require novel care strategies. Public policies, health-care regimes and technology developers alike stress the need for individualized care to meet the increased demand for care services in response to demographic change (Joyce and Mamo, 2006, Kenner, 2008).

Increasingly, care services are offered to individuals with diseases and or disabilities in their homes by skilled practitioners. Home-care services include, among other things, nursing care, medical- and social services (Cavoukian et al., 2010). Implemented in the homes of care 
recipients, personalized health-monitoring technologies can reduce (1) care recipients' need to visit health-care institutions as well as their need (2) for home visits by health-care professionals such as district nurses and by social-care providers such as home-help service staff. With the support of such technology, care providers can follow the health status of care recipients at a distance, limiting physical meetings to cases where care recipients have an acute care need. Despite a low level of direct involvement, care recipients' conditions can be monitored continuously. That is, blood glucose levels, ECG, blood pressure, lung function, body temperature and weight can be measured by sensors at a distance (Celler et al., 2003). Likewise, home-help service personell can, to a large extent, follow care recipients' doings without visiting them (Magjarevic, 2007). Remote camera- and sensor monitoring systems combined with alarm function ensure that home-helpers are informed in case of an anomaly or a critical occurrence (Steg et al., 2006). Integrated in the living environment of the care recipient, micro-sensors can record, store and transfer information about their daily activities to a care unit. Likewise, infra red night-vision cameras implemented in the bedrooms of care recipients allow care personell to conduct remote check-ups during the night without paying care recipients physical visits (Palm, 2010, 2012). Assistive technology can also reduce the extent of formal- and informal care providers' involvement in day-to-day tasks. Navigation support, movement sensors programmed to open and close doors, biometric gait-recognition technology indicating and warning a person at risk of falling are some examples of supportive technology developed for home use (Broekens et al., 2009).

One aspect of the broader category "home care" is "self-care". Public-health policies and bestpractice guidelines promote self-care as the model for future care. Self-care has been defined as "decisions and actions taken by someone who is facing a bealth problem in order to cope with and improve his or her health" (Romanow, 2002). It ranges from seeking relevant information, to undertake lifestyle changes or monitoring of vital signs and is often described as a complement to professional health-care for persons with chronic health-conditions. It should be noted however, that no single definition of self-care has gotten broad acceptance. Definitions of self-care vary as to the (1) parties involved e.g., individual, formal and informal care providers; (2) aims e.g., promote health, prevent illness, evaluate symptoms, limit the impact of illness, restore health; and (3) extent to which health-care professionals are involved (Secker et al., 2003).

Technology-based self-care can be executed by care recipients with or without the participation of health-care professionals. Various self-monitoring solutions are available such as diabetes selfmonitoring - often in the form of mobile phone-based applications, pedometers (Jarrett et al., 
2004), accelerometers (fall detectors) (van Coevering et al 2005) and self-monitoring of vital signs (Celler et al., 2003). A wide range of smart-medicine devices (Magjarevic, 2007) such as smartpill-containers (Palm, 2010) and textiles (Jul, 2008) are under development. Worn in clothing or watches, micro-sensors can measure individuals' vital signs and keep track of their health status. Such data can be transmitted to health-care units (Palm, 2010). Examples of more advanced forms of self-care in use are assisted ventilation-technologies (Fex, 2010). Monitoring systems of this kind enable, continuous attendance "without direct 24-hour supervision by formal or informal care providers" (Kenner, 2008). In combination, such technologies offer rather complex images of care recipients (Palm, 2010).

A shift in health-care locus carries several ethical implications that deserve analysis (Palm, 2012). Self-care equipment is typically said to empower care recipients, promote their autonomy and independence (Ellenbecker et al., 2008) - central concepts/aims within medicine and health care (Russel, 2007). In particular, measures to improve the quality of nursing care for elderly people are often motivated by independence (Davies et al., 1997). In-need persons are generally assumed to prefer self-care over traditional institutionalized care (Kenner, 2008). However, even if self-care is said to promote independence, the meaning and value of independence as used within health- and social care are seldom made sufficiently clear (Secker et al., 2003, Leece and Peace, 2010) - especially not in relation to elderly care (Grenier, 2003). The same hold for technology developers' usage of independence (Nordgren, 2011).

\section{Independence as used by policy makers, care providers and technology developers}

In the following section, examples will be given as to how self-care and independence are discussed by (1) health-policy makers, (2) health- and social care-providers and (3) developers of self-care technology.

Modern health-care plans and policies often advocate customer-choice models and care recipients' chances to influence the caring process (Szebehely and Trydegård, 2011). Care recipients are often portrayed as independent consumers - "health-care consumers" (Murray, 2007, Murray et al., 2007) who actively seek and choose suitable health-care programs for themselves. Aging-in-place i.e. the opportunity to receive care treatment at home rather than in care facilities has been presented as a more cost-effective alternative to traditional care. It is characterized as not "involving costly professional support unless necessary" (Lawler, 2001). Health-care costs can, it is argued, be reduced by minimizing the provision of inappropriate care and by flexible services calibrated to fit individual care-consumers' needs. Aging-in-place advocates state that individuals who get the opportunity to decide what type of assistance they 
prefer, when and where, gain control over their "independence, quality of life and dignity". ${ }^{2}$ By letting elderly persons receive the type of care they need in a setting of their own choice, their independence is safeguarded. ${ }^{3}$ Furthermore, "inappropriate support, either too much or too little, can undermine and binder the efforts of individuals to remain functionally independent, can shorten the length of their independent lives and severely cripple their ability to contribute to the social, civic and economic well-being of their communities" (Lawler, 2001). Independence and self-sufficiency are safeguarded by accommodating needs and interests defined by individual care-recipients. Coordinated health- and housing programs are said to help care recipients to maintain valuable social networks that often are lost as a result of relocation from home to assisted-living facilities. Such shifts often imply a significant loss in the quality of life, personal control and dignity (Lawler, 2001).

Within social care, independence is typically defined in relation to disabled individuals' capacity to perform self-care tasks (Leece and Peace, 2010). Likewise, elderly person's independence is measured in terms of their ability to manage daily activities on their own. An individual is considered independent to the extent that he or she can function unaided by formal careproviders. According to this understanding, assistive technology and self-care systems can promote independence. It is stated that individualized care-services can "help individuals to improve function and live with greater independence; to promote the client's optimal level of well-being; and to assist the patient to remain at home, avoiding hospitalization or admission to long-term care institutions" (Ellenbecker et al., 2008). Moreover, it is said that home-monitoring devices can help individuals with chronic or co-morbid health conditions to gain control by managing the distribution and coordination of care e.g. providing real-time, continuous or episodic biometric measurements of key health-state indicators. That is, care recipients can become co-managers of their health state together with a professional care-provider. This is said to offer "a tremendous opportunity to move from dependence to independence in self-care" (Ellenbecker et al., 2008). In some cases, health-monitoring technology and self-care systems are said to alleviate dependence preemptively. "Technology systems that encourage long-term care patients (e.g. seniors and those with chronic illnesses) to maintain their physical fitness, nutrition, social activity, and cognitive engagement, so they may function independently in their own homes, for as long as possible, can help to address the social and financial burdens of an aging population” (Cavoukian et al., 2010).

In advertisements, several technology developers describe their products as capable of enhancing the intended users' independence. In an overview of technology developers' rethoric in webadvertisements it is said that "independent living improves quality of life and also reduces health care costs"

\footnotetext{
${ }^{2}$ http://aginginplace.com

${ }^{3}$ http://www.aginghomehealthcare.com
} 
(Nordgren, 2011). Technology developers and system providers present personalized healthmonitoring technologies as a means to improve the quality of health care, safeguard security, empower care recipients, promote their independence and reduce costs (cf. Buller et al., 2009). ${ }^{4}$ Furthermore, they emphasize how their technology enables flexible support and allow care recipients to stay at home with a minimum of intervention from health-care providers (cf. Buller et al., 2009). That is, the technology enables care without the direct involvement of health-care professionals. Technology-based monitoring for home care use is launched as "remote" and "passive" contrary to the immediate and active monitoring of a care provider. Set up with personalized health-monitoring technologies at home, the care recipient is also said to be able to influence the care process to a larger extent than under a traditional care regime. Care recipients "may influence the kind and degree of monitoring, turn on and off the monitoring devices, and decide what shall be done with health information. Moreover, the patient's possibility to act more generally may increase i.e., the possibility to perform her daily life activities on her own" (Nordgren, 2011).

\subsection{An interpretation of independence as used}

In below, the meaning and value of independence as used by the different agents will be interpreted.

Analyzing the language of health-care plans and policies, a business terminology is frequently used. Care recipients are often referred to as independent "health-care consumers" (Murray, 2007) and the relation between professional health-care provider and health-care recipient is often described in terms of a partnership and co-management. This tendency to apply "corporate-governmental models of efficiency, accountability, and so-called evidence-based best practices" (Murray, 2007) in health care has been criticized for obscuring the real intent - to make money out of in need of care rather than offering what is in their best interest (Murray, 2007). Clearly, care recipients are taken to be active and responsible care consumers who select the care form that best suits their needs and interests. It is typically assumed that, when offered the choice, care recipients will prefer to receive treatment and/or services at home rather than in care institutions (OECD, 2000).

When care planners, care providers and technology developers discuss independence, it is in terms of a care recipient's relative need of support, care and assistance from others rather than, as in the OED-definition, complete self-reliance. Following the Oxford English Dictionary

\footnotetext{
${ }^{4}$ http://www.hhs.gov/myhealthcare/news/phc-report.pdf
} 
independence is defined as: "exemption from external control or support; freedom from subjection, or from the influence of others; individual liberty of thought or action (OED, 1989). It is more in line with a common-sense way, where independence tends to mean: not having to rely on others for support, intimately associated with achievement (Yates, 1991). Independence is not framed as an autonomous state of being but as achieved by separation from control by others or reliance on others for support. In particular, it concerns (1) control and self-determination and (2) freedom from reliance on formal care-providers. This is the ideal towards which care policies, services and technical support aim. Wisely designed, it is said, care regimes can maximize care recipients' self-reliance. A main concern is that despite a care need, individuals should be able to, as far as possible, function unaided in a location of their choice. Most importantly, unaided seems to be equated with not having to rely on the immediate involvement of care professionals. Whereas the need for support from health-care professionals is taken to denote dependence, a care need met by instrumented support is typically described in terms of independence. That is, self-care technology is said to promote independence.

Policy makers stress that aging-in-place programs enable "customized care" and that a freedom to choose and design care program serve to empower individuals with care needs. Independence is gained by access to alternative care forms and the chance to choose between different alternatives, thereby influencing the care process. This perspective resembles a view on independence communicated by disabled activists concerned with the care recipients' chances to exercise (meaningful) self-determination (Morris, 1997). Care planners, care providers and technology developers focus on technology-based strategies to achieve independence as goal or outcome i.e., avoiding dependence. Social-care providers define an individual's degree of independence by assessing the extent to which she can function without support from formaland/or informal care-providers for the execution of daily living activities. Individuals in need of support with every-day tasks are typically seen as dependent (Grenier, 2003). Based on such assessments, an individual with a care need can be offered self-care technology helping her to become less dependent on care providers' assistance.

From the perspective of technology developers, independence is often equated with receiving care at home and going on with one's ordinary life as far as possible. Technology developers claim that self-care technologies enable individuals with a care need to function unaided outside traditional care institutions. Health-monitoring technologies are said to enable independent living.

In order to sum up, none of the agents' understands independence in a strict sense. Key components of independence are: care recipients' ability to influence the care process and limited involvement from care professionals. Technological systems are said to promote care recipients' 
independence. Independence is promoted by (1) offering alternatives care forms for individuals to choose between, (2) the chance to negotiate and shape care provision, (3) the ability to remain at home and (4) to receive instrumented care, reducing the need for direct involvement of care providers. Independence seems to mean, freedom from reliance on human care providers formal or informal such. In the following, this particular understanding of independence will be referred to as "functional independence".

\section{Practical and ethical implications of independence as a goal for modern care}

As we have seen, independence is communicated as a central aim for future health-care and instrumented and customized care is presented as the means to improve this aim. Certainly, the notion of independence has a positive ring but what practical and ethical implications can be expected from such aims?

Home-monitoring devices allow both health-care professionals and family members to "keep a virtual eye on" frail elderly and homebound people with chronic illnesses. Care providers must no longer make physical calls on care recipients in order to check their health status. Cameras and sensors implemented in the homes of care recipients provide up-to-date information. Novel care technology renders physical meetings less important for the execution of care tasks but not necessarily less important for the realization of care goals. Home care may be both convenient and comfortable to care recipients. On the other hand, this type of home care will most likely have a significant impact on interpersonal relations (Cavoukian et al. 2010, Palm, 2012). With personal monitoring-devices set up in their homes, care recipients' needs for hospital visits or inhome attendance by professional care providers can be reduced (Palm, 2012). However, the importance of social relations for well-being is well-documented (Fine and Spencer, 2009) as well as patients' need for a certain type of recognition. Care professionals' measures to promote health are important, but not only in terms of successful outcome i.e. alleviating pain or curing, but the act of caring is said to be intrinsically valuable (Noddings, 1984). Emotional and social support are considered important aspects of home care (Szebehely and Trydegård, 2011). Physical meetings may be crucial to the realization of well-being, feelings of security and relations of trust. If replaced by assistive technology and tele-care - a most important aspect of caring may be lost.

Continuous monitoring offers care providers access to timely health information, enables data aggregation, pattern-recognition and detection of anomalies most useful for making reliable diagnoses (Cavoukian et al, 2010). Care providers access to data and chances to process personspecific health data are significantly improved. Yet, unless continuous data collection is paired 
with interpersonal meetings between care recipient and care provider, important types of information may be left aside. Many of the cues that a health-care professional would pay attention to in a face-to-face meeting with a patient and make use of when forming an opinion of the patient's general condition are most likely missed in a care system with tele- rather than real life meetings. Another aspect of relevance for the quality of remote care is that of trust and confidence. Ideally, the relation between care provider and care recipient should be characterized by trust. Interpersonal trust is crucial due to information- and competence asymmetries between practitioner and patient. Without trust care patients may refrain from disclosing medically relevant information to the health-care professional and even refrain from seeking help when in need of care (Rowe and Calnan, 2006). Thus, the impact of care provision from a distance on trust in the patient - physician relation remains to be investigated. As of yet, it is unclear if cues are sufficiently well transmitted during electronic meetings like Skype-calls. Until more knowledge is gained, fact-to-face meetings should not be substituted with distance health monitoring and supplemented with caution. Self-care systems may alter the relation between health-care professional and care recipient - an aspect that merits recognition in care planning.

\section{Social isolation}

A survey of factors crucial for health- and well-being identifies personal networks as keys to selfrespect, social integration and support (Fine and Spencer, 2009). Embedded in social relationships, individuals experience a higher level of well-being than if socially isolated. They also tend to be healthier. Social networks are said to imply (1) appreciation, recognition and a feeling of belonging, (2) intimacy and friendship and (3) emotional and practical support (Fine and Spencer, 2009). In times of need, individuals with a social network can count on advice or concrete help to solve a problem. Social isolation is described as a combination of limited social interaction paired with feelings of loneliness. Individuals who live alone, lack intimate partners, contact with friends and family and other social networks are prone to feel lonely (Fine and Spencer, 2009) and perceived social isolation has a negative impact on individuals' health condition (Cacioppo et al., 2002). Social connectedness is of importance for individuals to be able to cope with excessive stress (Secker, 2003). Importantly, perceived social isolation has been identified as a growing problem in relation to home care (Cacioppo et al., 2002, Burns and Haslinger-Baumann, 2008). Whereas inpatients benefit from daily interaction with health-care professionals, recipients of self-care technology may become socially isolated during their convalescence - especially individuals who live on their own and/or have a limited social network (Palm, 2012). The latter may be true of all patient types but in particular of elderly people with 
chronic diseases and limited social networks who, to an increasing extent, receive care provision in their homes.

Certainly, some policy documents stress the importance of social companionship for health and well-being. Aging-in-place programs are even claimed to promote social connectedness by preventing relocation to assisted living facilities (Lawler, 2001). However, in order for self-care to work as intended, the social component must be properly recognized. A failure to take into consideration care recipients social connectedness, self-care may result in creating rather than alleviating ill-health and replacing one health problem with another.

\section{Self-care in the private domain}

Another argument held forth in favor of self-care is that it enables care recipients to remain in their private realm, where they feel at ease, thus promoting comfort. "Home is a place of emotional and physical associations, memories and comfort" (Tarricone and Tsouros, 2008:vii) as well as "a place of confidence, where one can trust the other, where one feels comfortable, safe, and where one's privacy is most respected" (Dekkers, 2009). Elderly people are generally reluctant to move to a new environment. At the same time they are often forced to do so. For them, a home plays a critical role in maintaining a sense of personal identity and independence, sustaining a meaningful existence, and resisting institutionalization (Dekkers, 2009). It has been framed as "a repository of memory, continuity and tradition" - especially for old people (Secker et al., 2003), even as "an extension of personality" (Townsend, 1963). However, a poorly recognized aspect of the modern technology-based home care is how it influences care recipients' privacy.

Self-care is said to enable a more comfortable alternative to institutionalized care. Advanced home-care technology has the potential to alter the domestic sphere significantly - a change that care recipients may find difficult to adjust to. Once their private domain is transformed to a "hospital-like environment" care recipients may not fully recognize their homes and/or may no longer feel as comfortable in their dwelling place. A constant presence of surveillance-capable technology in the domestic domain may alter the character and atmosphere of the home significantly. In a sense, care recipients may experience a loss of control over their private realm. Local privacy is also circumscribed in that many of the home-care technologies give care providers' "virtual" (remote) and physical access to the patients' home. A significant aspect of local privacy is a person's ability to control and restrict others' access to her private domain (home or dwelling place). This ability may be significantly circumscribed with surveillance capable equipment at home such as movement-sensors registering and reporting information about activity and inactivity to a care unit. 
Sensors integrated in the patients' living environment and wearable monitoring-device feeding information about her health status and her doings to a care unit have impact on informational privacy. Although the care recipient must be aware of and have consented to the information being transferred, she may not be aware of how the information is processed and used. Ambient technology typically disappears in the living environment, becoming obsolete (Palm, 2010). Over time, a large amount of data has been collected - information that may be compiled and analyzed in ways beyond the data subject's awareness. Different types of information collected from sensors worn in clothing and integrated in the floors, walls and everyday objects in the domestic realm can be merged and, over time, offer rather complex images of the monitored individual. Thus, sensors can enhance security and safety but may also have a negative impact on patient autonomy and privacy (Palm, 2010).

An important feature of home-care technology is the ability to continuously register, store and transfer data from the private realm of the care recipient's home to the care provider. Even if care recipients have consented to have health-monitoring devices implemented in their homes, they modify their behaviour in response to the monitoring e.g. by altering their life style in accordance with the care provider's (assumed) preferences rather than in accordance with their own interests and wishes. Certainly, this may result in a healthier life-style but it may also imply a (slight) infringement in the care recipient's personal autonomy.

Privacy in relation to home-care technology is a highly complex matter. Such technology may protect some dimensions of privacy and intrude on other. If however privacy would be considered at an early stage in the development process "these technologies can actually increase the privacy of the individual by providing them with greater choice and personal control over how their data is managed. Individuals would have the option of receiving care from the privacy of their own home" (Cavoukian, 2010). A person who relies on constant attendance by care personell may appreciate monitoring device that allows her to, at times, be on her own without the physical presence of a care provider. To be under observation in one's own home may, in many ways, be perceived of as privacy sensitive. Traditionally, the home has been a secluded place, where we can restrict others' access and introspection. Furthermore, it should be noted that information collected by monitoring systems does not only concern the care recipient but may include third parties as well. Movement-sensor carpets can for instance register information about visitors coming and going. In a not too distant future, sensors programmed to recognize biometric features like gait can distinguish the care recipient's movements from that of visitors. Hence, privacy issues related to home-care technology merit attention. For instance, the extent to which privacy intrusions are experienced 
are likely to vary with the duration of technology-based assistance in the home i.e. whether longterm care, postoperative monitoring, and terminal palliative care.

\section{Freedom or burden of choice?}

Care planners and technology developers hold forth freedom of choice regarding care provision as a positive thing. Access to a broad range of health-care services is taken to improve the care recipients' freedom of choice. Certainly, care recipients are treated to a rich smörgåsbord of care services and can tailor a care-model that serves their particular needs and interests. However, whether or not this freedom to choose between a large number of self-care alternatives will be perceived as a benefit is likely to depend on care recipients' over-all situation including aspects such as care need, civil status and social network. Some may find it stressful to seek and process information necessary for well-informed decision-making regarding their care provision. It may be difficult to estimate one's (physical/cognitive/emotional) capacity to deal with self-care technology and the impact on the household and its members. Freedom of choice regarding health-care provision is generally considered a positive thing. However, for some individuals the need to choose between technology-based care alternatives may be overly demanding - especially for individuals who live alone. In a Swedish study on elderly peoples' attitudes to novel assistive technology, elderly couples were asked to evaluate scenarios were they, as health care recipients, would be set up with technical support at home as a complement to ordinary care provision (Essén, 2008). In some of the scenarios, the users were described as co-habitants, in others the user would be living on his or her own. The couples participating in the study expressed a positive attitude to assistive technology in the scenarios where the users were described as cohabitants but were significantly less positive in cases where users were living on their own. As couples they were confident that they would be able to learn about and manage novel care technology together but living on their own, the technology would rather be perceived as stressful. Their confidence in dealing with novel assistive technology at home depended on support from a co-habitant. Access to back-up and support from familiar and trusted health care professionals were also aspects that made the elderly couples positive to home care technology. More to the point, interviewees were generally positive to the technology as a complement (provided partnership and contact with health-care professionals) but skeptical to the technology as a substitute to ordinary care (Essén, 2008). But, this is not to say that elderly will be more reluctant to novel technology than what younger individuals will be. Variances in preferences will be seen among individuals across age groups. Individuals are risk aversive and risk prone to 
varying degrees irrespective of age. Regardless of age, individuals may experience self-care technology as stressful and burdensome.

Once set up with the preferred care alternative, the care recipient may experience self-care as overly demanding. With access to self-care technology, care recipients are typically expected to become involved in and take responsibility for the care process (Schermer and Kammen, 2004). Equipped with sophisticated health-care equipment at home, out-patients may find it practically and emotionally challenging to manage self-care device on their own (Fex, 2010). Technology that previously was used within acute care exclusively has been made easy-to-use, adapted to selfcare so that individuals with extensive care needs can be treated at home rather than hospitalized. Individuals with chronic conditions are set up with oxygen-, respirator- and dialysis equipment in their homes (Fex, 2010) and post-surgery treatment previously executed in institutionalized care, can now, to a large extent, be offered in the patients' homes. Likewise, post-stroke patients may be offered robotized rehabilitation treatment in their living environment (Dittmar et al., 2004) and assistive robotics can support care recipients in daily tasks (Bemelmans, 2010, Broekens et al., 2009).

Self-care typically requires that the care recipient become a co-manager in the care provision process. The extent to which care recipients are capable of, suited for and comfortable with such involvement and responsibility becomes relevant in relation to increased use of self-care and distance monitoring. If experienced as too demanding, care planners' ambitions with home care are likely to back-fire, creating stress and insecurity among the users.

Fears have also been expressed that users of personal health monitoring devices may come to think of themselves in terms of health parameters and form their identities foremost as patients (Collste, 2011). That is, continuous somatic surveillance may "foster" an identity as a patient. Care recipients self-understanding may be heavily influenced by an external "force" i.e. monitoring devices and have a negative impact on personal autonomy. Furthermore, self-care is likely to give rise to a new type of dependence. Within a self-care system care recipients may become less dependent on physical care providers but more dependent on electronic care systems and technological devices. Certainly, with self-care technology at home, out-patients can influence to a larger extent than in traditional interpersonal care in the sense that they can switch off devices (see: Nordgren, 2011). However, this may be true in cases of routine monitoring of vital signs but less accurate in cases of technology-based life-sustaining support e.g. by assisted ventilation technology. Arguably, the implications of this type of dependence deserve further attention. 


\section{A reasonable understanding of independence}

In previous sections, the usage of "independence" among agents involved in care provision have been presented together with analyses of reasons and implications of an emphasis of independence so understood. How then, should independence reasonably be framed in order to be a viable aim for future health care?

Independence has an important status in the Western society. Reflecting on the meaning and value of independence, it has been held forth as a virtue, "a quality that betokens health and maturity" (Yates, 1991). Moreover, it has been described as "the ability to do things for oneself, to be self-supporting and self-reliant" (Morris, 1997). Conversely, dependency in the Western society is, according to some, "to to be subordinate, to be subject to the control of others" (Morris, 1997). As previously described, policy makers' and care providers' strong emphasis on independence and measures to further that end send a clear message to individuals in need of support and care - dependence is an undesirable state that should be avoided as far as possible. Dependence has become socially stigmatized in the Western society (Joyce and Mamo, 2006) and several studies show how elderly people have internalized negative conceptions against elder as a group and against dependence (Minichello, 2000, Secker et al., 2003, Joyce and Mamo, 2006). Based on empirical studies, the case has been made that elderly people in the West wish to live on their own and minimize the need for assistance from formal- as well as informal care providers (Dekkers, 2009). Such preferences are often interpreted as a wish to remain independent. However, in/dependence is a complex matter - especially in relation to individuals of old age whose changing physical, interpersonal and financial resources may necessitate certain forms of support, irrespective of their previous preferences regarding dependency and autonomy. Some scholars argue that dependency is even more multifaceted in samples of elderly than among younger adults (Fiori et al, 2008).

Importantly, there are several dimensions; economic-, emotional-, physical- and domestic in/dependence can have many shapes and forms and occur in several domains. At least, independence can mean: (1) being able to look after oneself, (2) having a capacity for selfdirection and (3) not being indebted (financially and/or emotionally) (Secker et al., 2003). Thus, it should be recognized that the type of independence discussed by care providers, care planners and technology developers focuses on some while neglecting other - perhaps equally important aspects of independence. 
In below, some of the many facets of independence will be illustrated by means of examples from empirical studies.

In an interview study with 72 elderly Swedish women suffering from stroke, rheumatoid arthritis and Parkinson's disease but still living on their own, almost all interviewees stated that they feared dependence and did not want to become a burden. Since the interviewees' diseases significantly reduced their capacities and threatened their chances to remain living on their own at home, they had developed strategies to remain active and to postpone a state of dependence. Self-determination and maintenance of "order in life" were stated as reasons for wanting to remain independent. In this particular case, interviewees expressed a wish to be independent towards society as well as towards their relatives (Gustafsson et al., 2003). However, even if many people may share the wish to maintain order in life without assistance from relatives, this must not be equated with a wish for independence. Motivation to manage daily tasks on one's own can be but is not necessarily the same thing as a refusal to rely on others for support. It may for instance be a way to keep oneself active or a comfort to follow one's well-established daily routines. Moreover, the question is seldom either dependence or independence but a matter of degrees. Despite a care need, elderly people prefer to be self-sufficient and seek support foremost in emotionally difficult times - an attitude described as "healthy independence" (Fiori et al., 2008). And, individuals in need may accept support with some tasks but not with other and on whom one relies for the different types of support differ. An elderly parent may find it perfectly acceptable to rely on her children when in need for e.g. grocery shopping or filling out tax forms but for certain types of support she may rather rely on care professionals e.g. hygiene care and cleaning. In Finland and Sweden elderly people are said to prefer receiving assistance with hygiene care from care professionals rather than from their children (Genet et al., 2011). That is, for some services, care recipients may prefer relying on a care provider, for others on friends and family and for yet some, on assistive technology (Palm, 2012). Ties to other family members are significant for whom a person in need chooses to rely on and whether she opts for support from a care professional or kin-person. Also, the over-all situation of a caring kin-person is likely to matter. Studies indicate that many elderly people are prone to avoid support from their adult children out of a concern not to burden them (Secker et al., 2003). An elderly person's hesitation to involve adult children in the care-giving process may be an expression of respect for the private lives of the adult children, their needs and responsibilities rather than a quest for independence. That is, frail elderly people in need of assistance may assess their own needs and interests in the light of those of the needs and interests of their adult children. Once again, 
individuals' comfort with being dependent varies significantly and depends on a large number of factors.

\section{The relevance of independence}

Several scholars have questioned the usefulness and reasonableness of independence as an aim within health care since all people, healthy or sick, disabled or not, rely on others in several ways. Independence as self-reliance and self-government in e.g. the OED-definition, is considered untenable. In most cases, it is argued, individuals are dependent on the cooperation of others irrespective if they have a care need or not (Agich, 2009). "From cradle to grave, no matter how advantaged, educated, physically or mentally able a person is, he relies on a host of other people and a host of people rely on him" (Russel, 2008). In the course of everyday life, well-functioning adults interact with and depend on spouses, children, parents, families, friends, co-workers and service providers. And, for a wide range of services, they rely on specialists who "usually can deliver a quality service or product better than an individual can provide for themselves" (Agich, 2009).

Opponents of the prevailing status of autonomy and independence within health care typically view the self as inherently connected to the surrounding social environment and define the moral agent (and agency) in terms of social relations. According to disabled activists, independence should be understood in terms of control over care provision, not in terms of the actual execution of care services (Morris, 1997, Oliver, 1989). "Independence is not linked to the physical or intellectual capacity to care for oneself without assistance, independence is created by having assistance when and how one requires it" (Morris, 1997:56)..$^{5}$ A personal assistant can be employed to help a person in need of support to carry out routine tasks and "if such functions are performed under the control of that person it is really a moot point whether the person physically performed the activity" (Wehmeyer, 1998). The case is made that in order for a person to be independent, it is sufficient that she can make autonomous decisions regarding where and how to live and with what type of assistance (cf. Morris, 1997, Oliver, 1989).

The traditional understanding of independence as a matter of self-reliance and self-sufficiency corresponds well to the liberal tradition within philosophy whereas the opposing perspective described above, resembles the communitarian tradition. One of the major demarcation lines between the liberal and the communitarian tradition is the view on the extent to which the moral agent is considered independent from society. Following communitarians, moral agents are typically embedded in a web of social relations and part of a community that shapes their identity.

\footnotetext{
${ }^{5}$ http://www.leeds.ac.uk/disabilitystudies/archiveuk/morris/constructing $\% 20$ an $\% 20$ ethics $\% 20$ of $\% 20$ care $\% 20$ which
} $\% 20$ promotes $\% 20$ human $\% 20$ rights.pdf 
Communitarian scholars emphasize the importance of communities such as the family, the neighborhood, associations, churches and the political community, for the shaping of a person and criticize liberal scholars for a tendency to describe moral agents as free-floating, independent individuals and for neglecting the significance of the social context. ${ }^{6}$

However, the disabled-rights advocates' descriptions of independence above are conflated with autonomy. They argue that by letting care recipients exercise their discretionary power and influence the caring process, their independence can be safeguarded. Clearly, personal selfdetermination i.e. the ability to control one's life and fate, is an important component of independence (Wehmeyer, 1998). The freedom to choose and the ability to influence one's care situation are necessary aspects but insufficient as criteria for independence in the context of health care. Although self-determination makes up a significant part of independence, in addition, the importance of self-reliance (Secker et al., 2003) and self-sufficiency should be recognized. All three aspects are necessary for an individual to be independent in a meaningful sense. Selfreliance typically means to rely on one's own "capabilities, judgment, or resources" and selfsufficiency: to "provide for oneself" (Wehmeyer, 1998). An independent person can manage on her own without the support and guidance by others in everyday life. As we have seen above, self-determination and self-sufficiency are emphasized and the significance of self-reliance downplayed. It is often considered enough to rely one's own judgment and resources (not just monetary) to identify an agent who can provide a desired outcome (Wehmeyer, 1998). The importance of self-reliance and capabilities should be recognized as well.

In most practical cases, individuals with significant physical and cognitive disabilities can be involved in and influence the decision-making or problem-solving of care provision. Even a person with a significant cognitive impairment who cannot make a decision alone without support can be coached to make a complex decision or solve a difficult problem (Wehmeyer, 1998). By involving individuals in need of assistance in the decision-making regarding and design of care, their care situation will reflect their preferences and respect their autonomy. Strategies can be employed to promote care recipients' chances to influence the caring process. Likewise, self-care technology and support programs can reduce their need for manual support. Thus, in many ways, self-care technology and support systems can help individuals with significant disabilities to function as autonomously and independently as possible. What is obtained by such strategies is foremost a freedom from direct involvement by care professionals (formal or

\footnotetext{
${ }^{6}$ It should be noted that communitarianism is a label for a direction within social and political philosophy rather than a homogenous school of thought. In order to understand e.g. human identity and well-being the importance of the community is emphasized.
} 
informal). Rather than rephrasing the meaning of independence, the value of independence merit further attention.

Obviously, as members of a community, individuals are practically, socially and emotionally dependent on others for their upbringing, education, well-being etc. In this sense, we are all interdependent on cooperation. Most of us rely on others and a large number of services in order to live a comfortable life (Reindal, 1999). Yet, this is reliance is normally not discussed in terms of dependence. Individuals in need of home care and home help services however, are often described as dependent (Grenier, 2003). This can be illustrated by means of the following examples. If a person hires a plumber to have pipes and backwater valves installed or repaired at home, his or her independence would most likely not be questioned. Rather, he or she would be seen as someone having recruited professional assistance with a task beyond his or her area of competence. Likewise, by making an appointment with a hairdresser to have one's hair cut, one would not be considered independent. However, an individual contracting a care professional in order to get assistance with qualified daily living-activities may well be considered dependent. Why are individuals who employ plumbers and hairdresser typically are seen as independent consumers of certain services whereas individuals ordering home-help or care services are not? Possible explanations to be considered are:

(1) The complexity of the task to be conducted - the extent to which one can do X on one's own.

(2) The duration of the task to be conducted.

(3) The type of need that prompts the task.

Whether or not the person requesting help with the specific task X could have conducted $\mathrm{X}$ on his or her own could be a relevant aspect for the ascription of in/dependence. Although some of us, despite adequate training, could execute the plumbing and hair-dressing on our own, it would most likely require a lot of time and effort and perhaps also result in a suboptimal outcome. Letting a professional do the work may simply be an effective way to secure a satisfying result (and for some services such as plumbing we may be legally required to employ a professional). However, this does not explain the differences in ascriptions of dependence and independence satisfactorily. In a similar vein, individuals with a light care need may order home-help service in order to have house-hold tasks carried out with a satisfying result even if they could execute the tasks on their own with a suboptimal result (comparable to that of plumbing on one's own). Perhaps then, the duration of the services is of relevance? Whereas plumbing and hair-dressing are conducted at a specific time, home help service is typically provided over a longer period of time. Care provision may be executed over time in a form of open-ended contract. Although 
individuals in need of home-help services typically rely on more frequent assistance, the duration or frequency of the task does not seem to matter. If a person would have her hair styled by a professional every day, she would not be considered less independent thereby. Rather, the difference seems to be connected with the underlying type of need. Assistance with daily livingactivities is typically considered to be anchored in vital needs in a sense that plumbing and hairdressing are not. Without adequate support, a functionally impaired person may not be able to live a dignified life - perhaps she may not even be able to survive on her own. Individuals with complex care needs may be incapable of executing daily living activities even with a suboptimal result. As default however, in daily use, individuals in need of home-help services are often referred to as dependent whether their care need is extensive or not. Rather, the need for home help is seen as a sign of independence (Grenier, 2003). Arguably, what is needed is not a novel interpretation of independence - as suggested by disabled rights advocates - but a new way of respecting dependence. Since individuals are interdependent and need assistance from others in the course of a healthy productive life, dependence should not be looked down upon irrespective of in what domain it occurs. Individuals in need of care provision should be in their right to be dependent if they so wish.

A significant risk with today's strong emphasis on independence (assumed to be a shared preference and) as the aim for future health-care, is that dependence is rendered a socially unacceptable state. Today, this message is clearly expressed within health care. However, the extent to which individuals in need of support are comfortable relying on others for support vary. If not portrayed as a "luxury preference", a significant number of people would probably ask for direct, physical assistance by flesh and blood care providers. However, given the strong emphasis on independence, those who are comfortable with dependence on care providers for assistance may come to opt for instrumented care provision e.g. robot- or sensor based care for the reason that direct care does not seem a viable option and/or for the reason that they do not wish to be a burden. A care recipient may be aware that the care form she prefers is resource demanding and that care providers prefer that she choses a less costly alternative. In order not to burden the system, care recipients may opt for resource-effective, instrumented care forms even if they personally would prefer resource-intensive personal assistance.

To what extent then, can technology-based self-care be said to promote independence?

As previously mentioned, independence has several dimensions. The technology is said to enable independence. It may, reduce the need for immediate assistance by care professionals and 
enable the care recipient to remain at home and go on with her life as far as possible despite the care need. However, as long as the care need remains the care recipient will be dependent on assistance, whether if comes from flesh and blood persons or technologies. Hence, what should be promoted in the context of health care is functional independence rather than independence proper. It should also be recognized that independence may but must not be something positive. If a voluntary option, self-care may be considered an empowering form of care, positive in terms of independence. If not freely chosen however, independence may become perceived as enforced.

\section{Conclusion}

Personalized health-monitoring technology is said to enable flexible care provision, allowing individuals to design a care program that suits their preferences, needs and over-all situation and is presented as the care of the future. Such care, often discussed as self-care is said to respect and promote care recipients' autonomy and independence - key values within the traditional health care system. Care planners and technology developers use these concepts frequently but for the most, without specifying them. The absence of clear directives motivates a discussion of the following questions: What do these values mean in relation to self-care? And to what extent should they be promoted?

Personalized health-monitoring technologies may well enhance the quality of care, safety and promote independence. However, the very same technologies may lead to stress and social isolation among care recipients and (formal and informal) care providers (Palm, 2012). A concern raised in this paper is that self-care may carry a negative impact on care recipients' well-being in that it may cause stress and insecurity. Self-care may also be to the detriment of social contact patterns, the quality of care and local privacy. Remote monitoring may replace interpersonal contacts (Palm, 2010, Nordgren, 2011). Hence, benefits of independence and comfort of receiving care at home should be carefully balanced against those risks.

Certainly, the relevance of autonomy and independence as ideals within health care and social care have been questioned before. Scholars critical of the status of traditional autonomy and independence have suggested relational autonomy and interdependence as more promising alternatives to the traditional notions that better respects the human condition (cf. Russel, 2008). However, those critical perspectives often imply a conflation of autonomy and independence. Autonomy and self-determination are important to an individual's independence but in order for a person to be independent in a meaningful sense, a certain amount of self-reliance is necessary 
as well.

Access to a broad range of self-care technologies seems to strengthen care recipients' chances to influence and design a care model that suits them (it should be noted that this opportunity may be demanding to some - develop). Except for some assistive technologies, self-care technology does not necessarily make care recipients self-reliant. Self-care is likely to decrease a dependence on formal care providers but may well increase the need for support from informal care providers (Palm, 2012) and most definitely, it implies a dependence on health care technology and systems. Where technology developers and care planners hold forth that personalized health monitoring technology promote independence, independence is often equated with the ability to remain at home, yet receiving the support one needs, and in reduced reliance on physical healthor social care providers. Technology developers and care providers alike seem to consider dependence on technical systems preferable over reliance on human beings. It may be less socially stigmatized but may also, in the long run, lead to social isolation.

So, in order to answer the question: to what extent are self-care and independence reasonable aims for future care? A shift in attitude towards dependence (as an entitlement) is much needed.

Acknowledgment: This paper is written within the project Personalized Health Monitoring Ethics (PHM-Ethics) funded by the European Commission (contract number 230602).

\section{References}

Agich, G. "Respecting the Autonomy of Elders in Nursing Homes" chapter in:. Morrisson, E.E. (Ed) (2009) Health Care Ethics. Critical issues for the 21 th century. Second Edition, Jones and Bartlett Publishers International, Mississsauga, Canada.

Bemelmans, R., Gelderblom, J. G., Jonker, P. and L. De Witte (2010), Socially Assistive Robots in Elderly Care: A Systematic Review into Effects and Effectiveness, Journal of the American Medical Directors Association.

Broekens, J. Heerink, M and H., Rosendal. (2009) Assistive social robots in elderly care: a review. Gerontology, 8(2):94-103.

Buller, W. Johnson, K. and P. Wilson (2009) Aging Well in a Connected World, CISCO Point of view.

http://www.cisco.com/web/about/ac79/docs/pov/Aging_Well_POV_FINAL040309. pdf

Burns, E. and E. Haslinger-Haufmann, Evaluation of the nursing diagnosis "social isolation" and the use of evidence-based nursing, Pflege, Feb;21(1):25-30. 2008. 
Cacioppo, J.T., Hawkley, L.C., Crawford, L.E., Ernst, J.M., Burleson, M.H., Kowalewski, R.B., Malarkey, W.B., Van Cauter, E., \& Berntson, G.G. (2002). Loneliness and health: Potential mechanisms. Psychosomatic Medicine, 64, 407-417.

Cavoukian, A., Fisher, A., Killen, S. and D. Hoffman (2010). Remote Home Health Care Technologies: How to Ensure Privacy? Build It In: Privacy by Design. Identity in the Information Society 3 (2):363-378.

Celler, B., Lovell, N. and J. Basilakis (2003). Using information technology to improve the management of chronic disease. Medical Journal of Australia 179(5): 242-46.

van Coevering, P., L. Harnack, K. Schmitz, J. Fulton, D. Galuska and S. Gao (2005). "Feasibility of using accelerometers to measure physical activity in young adolescents." Medicine and Science in Sports and Exercise 37(5): 867-71.

Collste, G. (2011) Under my skin. The Ethics of ambient computing for personal health monitoring. In:. The Handbook of Emergent Technologies in Social Research. Red. S. BiberHesse, s. 89-110. Oxford, Oxford University Press.

Davies, S, Lakers, S and L. Ellis (1997) Promoting autonomy and independence for older people within nursing practice: a literature review, Journal of Advanced Nursing, 26 (2) 408-417.

Dekkers, W. (2009). On the Notion of Home and the Goals of Palliative Care. Theoretical Medicine and Bioethics 30 (5).

European Commisson Information Society and Media Directorate-General (2011) Report on the public consultation on eHealth Action Plan 2012-2020, http://ec.europa.eu/information_society/activities/health/docs/policy/ehap2012publicconsult-report.pdf

Ellenbecker, CH., Samia, L., Cushman, MJ and K, Alster (2008), Patient Safety and Quality in Home Health Care. In: Hughes RG, editor. Patient Safety and Quality: An Evidence-Based Handbook for Nurses. Rockville (MD): Agency for Healthcare Research and Quality (US); Chapter 13.

Essén, A. (2008) The two facets of electronic care surveillance: An exploration of the views of older people who live with monitoring devices. Social Sciences \& Medicine, 67 (1) pp.128136

Fex, A. (2010) From Novice Towards Self-Care Expert - Studies of self-care among persons using advanced medical technology at home, Doctoral thesis, Division of Nursing Science, Department of Medical and Health Sciences, Faculty of Health Sciences, Linköping University, Sweden.

Fine, M. and R. Spencer (2009) Social Isolation - Development of an Assessment Tool for HACC services. A literature review conducted for the New South Wales Department of Disability, Ageing and Home Care (DADHC). http://www.nsforum.org.au/files/HACCMisc/HACC-Resources/FineSpencer-DADHCSocialIsolationProject09FINAL.pdf

Fiori, K., Consedine, N. and C. Magai (2008) The adaptive and maladaptive faces of dependency in later life: Links to physical and psychological health outcomes, Aging \& Mental Health, 12, (6) pp. 700-712. 
Genet, N., Boerma, W., Kringos, D., Bouman, A., Fagerström, C., \& Melchiorre M. G. (2011). Home care in Europe: A systematic literature review. BMC Health Services Research

Grenier, A.M. (2003). Unhinging the Assumptions Within Independence - Toward a Broader Conceptualization of Diversity and Difference in Home Care, Canadian Review of Social Policy/Revue Canadienne de politique sociale, Spring/Summer No. 51.

Gustafsson, K, Andersson, I, Andersson, J, Fjellström ,C. and B, Sidenvall (2003) Older women's perceptions of independence versus dependence in food-related work. Public Health Nursing May-Jun; 20(3):237-47.

Intel Health (2007) Chronic Care at the Crossroads. Available at: http://www.intel.com/healthcare/Chronic_Care_\%A0at_Crossroads_White_Paper.pd

Jarrett, H., Peters, D. and P. Robinson. (2004). Walking the way to health initiative: Evaluating the 2003 'Step-o-meter' loan pack trial. Final report. http://www.whi.org.uk/details.asp?key $=\mathrm{E} 14 \% 7 \mathrm{C} 0 \% 7 \mathrm{C} 42663490963 \% 7 \mathrm{Cp} \% 7 \mathrm{C} 66 \% 7 \mathrm{C0}$

Joyce, K., Mamo, L. (2006) Graying the cyborg: New directions in feminist analyses of aging, science, and technology. In T.M. Calasanti \& K.F. Slevin (eds), Age Matters: Realigning Feminist Thinking. New York, NY: Routledge, 99-121.

Jul, L. (2008). Adding values-Smart textile options for automotive applications. The Nordic Textile Journal. http://www.smarttextiles.se/filer/CTF_JOURNAL 0108.pdf.

Kenner, A.M. (2008) Securing the Elderly Body: Dementia, Surveillance, and the Politics of "Aging in Place", Surveillance \& Society 5(3): 252-269

Kinsella, K., \& Velkoff, V. A. (2002). The demographics of aging. Clinical and Experimental Research, 14, 159-169.

Lawler, K. (2008) Aging in Place. Coordinating Housing and Health Care Provision for America's Growing Elderly Population, Joint Center for Housing Studies of Harvard University Neighborhood Reinvestment Corporation (JCHS) http://www.jchs.harvard.edu/sites/jchs.harvard.edu/files/lawler_w01-13.pdf

Leece, J. and S. Peace (2010). Developing new understandings of independence and autonomy in the personalised relationship. British Journal of Social Work, 40(6), pp. 1847-1865.

Lyon, D., (2003) Surveillance as Social Sorting: Privacy, Risk and Digital Discrimination, Edited by David Lyon, New York: Routledge.

Magjarevic, R. (2007) Home Care Technologies for Ambient Assisted Living, http://home.mit.bme.hu/ kollar/papers/test-citex/IFMBE-319.pdf

Minichello, V., Browne, J. and H. Kendig (2000) Perceptions and consequences of ageism: views of older people. Ageinges Society, 20:253-278. 
Monahan, T. and T. Wall (2007) Somatic Surveillance: Corporeal control through information networks. Surveillance \& Society 4(3):154-173.

Morris, J. (1997). Care or empowerment? A disability rights perspective. Social Policy \& Administration, 31, (1):54-60.

Murray, S.J. (2007) Care and the self: biotechnology, reproduction, and the good life, Philosophy, Ethics, and Humanities in Medicine, 2:6 DOI:10.1186/1747-5341-2-6

Murray, S.J. Holmes D, Perron A, Rail G. (2007) No exit? Intellectual integrity under the regime of 'evidence' and 'best-practices'. Journal of evaluation in clinical practice. 13: 512-516 DOI: $10.1111 /$ j.1365-2753.2007.00851.x

Noddings, N (1984) Caring: A Feminine Approach to Ethics and Moral Education. Berkeley: University of California Press, 1984.

Noel, H., D. Vogel, et al. (2004). Home telehealth reduces healthcare costs, Telemedicine Journal and e-Health 10(2):170-183.

Nordgren, A. (2011) The Web-Rhetoric of Companies Offering Home-Based Personal Health Monitoring, Health Care Analysi, DOI: 10.1007/s10728-011-0174-z

OECD Health Policy Studies Improving Health Sector Efficiency: The Role of Information and Communication Technologies, June, 2010. http://www.oecd.org/dataoecd/20/23/2431724.pdf

Oliver, M. (1989). Disability and dependency: a creation of industrial societies. In L. Barton (Ed.). Disability and Dependency (pp. 6-22). London: Falmer Press.

Palm, E (2010) The ethics of mobile health care, Nordic Journal of Applied Etbics, 4 (2).

Palm, E. (2012) "Who cares? An analysis of ethical implications of technology-based home care" forthcoming in Health Care Analysis.

Reindal, S.M. (1999). Independence, dependence, interdependence: some reflections on the subject and personal autonomy. Disability \& Society, 14, (3):353-367.

Romanow, R. (2002) Building on Values: The Future of Health Care in Canada, Final Report Commission of the Future of Health Care in Canada, ISBN 0-662-33043-9.

Rowe, and Calnan, (2006) Trust relations in health care-the new agenda, European Journal of Public Health 16(1): 4-6. doi: 10.1093/eurpub/ckl004

Russel, B. (2007) The Crucible of Anorexia Nervosa, Journal of Ethics in Mental Health ISSN: 19162405

Schermer, M. and J. van Kammen, (2004) Advanced home care technology: moral issues surrounding a new healthcare practice, The Netherlands, Council of Public Health and Healthcare.

Secker, J., Hill, J., Villenaeu, L. and S. Parkman (2003). Promoting independence: but promoting what and how? Aeging \& Society. 23. pp.375-391. DOI : 10.1017/S0144686X03001193 
Steg, H., Strese, H., Loroff, C., Hull, J. \& Schmidt, S. (2006). Europe Is Facing a Demographic Challenge - Ambient Assisted Living Offers Solutions. Berlin, Germany: VDI/VDE/IT

Szebehely M and G-B Trydegård (2011) Home care for older people in Sweden: a universal model in transition, Health and Social Care in the Community. doi/10.1111/j.13652524.2011.01046.x/ full

Tarricone, R. and A. D. Tsourous (eds) (2008) The Solid Facts: Home Care in Europe. Copenhagen, World Health Organization, viii, 36 p. ISBN: 9789289042819

Townsend, P. (1963) The Family Life of Old People: An Inquiry in East London. Penguin. Harmondsworth. Middelsex.

UN report (2009). World population prospects: The revision 2008, United Nations, New York. http://www.economist.com/node/13888053 Commission of the European communities Brussels, SEC (2008) 2911 Commission staff working document Demography report 2008: Meeting social needs in an ageing society, executive summary.

Wehmeyer , M.L (1998) Self-Determination and Individuals With Significant Disabilities: Examining Meanings and Misinterpretations, Research and Practice for Persons with Severe Disabilities (RSPD) 23(1):5-16

Yates, A (1991) Compulsive Exercise And The Eating Disorders: Toward an Integrated Theory of Activity. New York, Brunner/Mazel. 